DOI: https://doi.org/10.15688/mpcm.jvolsu.2021.1.5

UDC 514.7

Submitted: 17.07 .2020

LBC 22.151

Accepted: 02.11.2020

\title{
THE USE OF THE MCNP CODE FOR RADIATION DAMAGE CALCULATIONS
}

\author{
Mohammad Qadr Hiwa \\ Assistant Lecturer, Department of Physics, College of Science, \\ University of Raparin \\ hiwa.physics@uor.edu.krd \\ https://orcid.org/0000-0001-5585-3260 \\ Main St, Ranya, Iraq
}

\begin{abstract}
This work gives a detailed analysis of the result of Monte Carlo physics practical using MCNP. This paper describes basic concepts of the Monte Carlo theory of radiation transport calculation and also discusses the variance and the history method as used in Monte Carlo Problem solving. Therefore, in this exercise the MCNP code has been used to solve and estimate the number of neutron flux. The paper investigates the impact of the primary radiation damage in iron by neutron energy irradiation. The established measurement of radiation damage is the displacements per atom (dpa) in matter as a function of neutron energy. The simulations were carried out to calculate the dpa cross section.
\end{abstract}

Key words: neutron damage, MCNP, displacement per atom, NRT, computational algorithms.

\section{Introduction}

Monte Carlo Method is a type of computational algorithms that depend on recurring random sampling in computation of results. It is used to simulate mathematical and physical systems. Monte Carlo Method is used to simulate systems with coupled variances like fluids [3;21]. Monte Carlo Methods find their use in oil and space exploration where it is used to predict failures, schedule and cost overruns [10]. In all its application Monte Carlo Method has yielded better results than any other method that can be used. There are different approaches in Monte Carlo Method. All these approaches follow a certain pattern where they define a possible input domain and arbitrarily generate inputs from probabilistic distribution. These methods also perform deterministic input computation giving the combined results. This method has been used to solve complex particle interaction problems in physics. The

(2) stochastic process used by Monte Carlo Method gives a model of a problem that would 
otherwise have been hard to solve given discrete solutions. As such, Monte Carlo is can be defined as a simulation method that describes a system of an experimental method. There are three types of simulation methods that are used; functional classification, that includes deterministic characteristics that give the same result whenever they are used and stochastic characteristics that are random in nature and may give different results when they are used. Due to their random nature stochastic functional classification requires numerous runs to determine a trend in the collection of results [24].

With developing nanophysics Mote Carlo N-particle transport cod (MCNP) is considered and widely utilized for neutron, proton and electron transport or coupled neutron/proton/electron transport. Moreover, MCNP is a software package program, which can be importantly used for analyzing nuclear processes (the transport of neutrons and gamma-rays) [4]. It was first understood in 1970 by for neutron and proton transport and it has been improved by the Mote Carlo team at LANL Los Alamos National Laboratory [6]. The MCNP code deals with transport of gamma-rays, neutrons and coupled transport such as secondary gamma-rays resulting from neutron interaction, the code can also deal with electron transport, both primary and secondary electrons source generated as a result of gamma-ray interaction $[9 ; 12]$. And it is also capable of estimating charged particle interaction of more than 34 different kinds of charged particles (ions and nucleons). In the term of nuclear process MCNP can be widely applied for many fields such as nuclear safeguards, nuclear medicine, nuclear criticality, dosimetry, radiation shielding, radiation protection, accelerator application, etc [15-17]. MCNP can employs cell card, surface card or other physical property card [12] which they can describe the geometry definition of the matter or they can also report to simulate the particle distribution. Interaction of neutrons with transition metal has been studied by many research groups $[11 ; 22 ; 23]$. This paper investigated the effects of primary radiation damage formation in metal.

\section{Radiation damage mechanisms}

The first atom hit by any type of incident radiation particle is referred to as the primary knock-on atom (PKA) which is of significance because secondary atoms then interact with this PKA and may also displace, as atoms are can be displaced from their atom site [27]. They are usually forced into an interstitial lattice site (assuming a defect free lattice) creating a self-interstitial atom (SIA) and vacancy pair also known as a Frenkel pair analogous to an electron-hole pair in a semiconductor. The PKA may have sufficient energy to cause a cascade of displacements, this usually consists of depleted zone of vacancies surrounded by the newly interstitial atoms. From this displacement spike the crystallography of the sample will channel the transport of the defects throughout the material in more open directions of the crystal lattice [29]. Figure 1 shows the scheme of neutron damage.

As protons have a Coulomb interaction whilst neutrons can be treated as hard spheres they have different recoil spectra depending upon energy, therefore a way correlate damage between different types of irradiation is needed as flux does not take account of a materials specific response to that type of radiation, the unit of displacements per atom (dpa) is commonly used for this reason although the microstructural mechanisms should be considered in each experiment for reliable simulation of neutron damage $[8 ; 18 ; 19]$.

There are numerous methods of describing material damage, the most common of which is dpa. Many different ways were developed in order to calculate dpa. Kinchin and Pease $[1 ; 20]$ were the first ones to come up with a great technique. The assumption was 


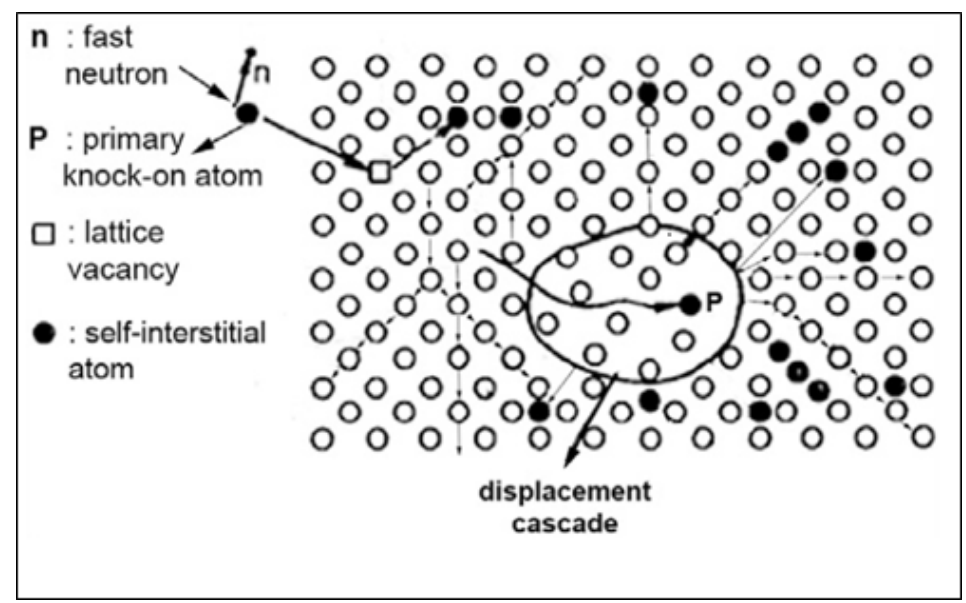

Fig. 1. A displacement cascade schematic which illustrates effect of crystallography of the material on the Frenkel pairs [2]

there was a linear relationship between the number of Frenkel pair produced and the initial energy of a PKA. After that, Kinchin and Pease (K-P), many authors tried to establish a new and better technique for calculating dpa. The most successful ones were Norgett, Robinson and Torrens (NRT) [13]. They developed a method for calculating dpa for a PKA with a given energy. This type of calculation is very interesting because it makes the comparison of different types of radiation easier. The NRT model gives the number of stable Frenkel pairs produced by a PKA with energy $E_{P K A}$ as given by [14]:

$$
N_{d}=\left[\begin{array}{cc}
0 & T_{d}<E_{d} \\
1 & E_{d} \leq T_{d}<\frac{2 E_{d}}{\beta} \\
\frac{\beta T_{d}}{2 E_{d}} & \frac{2 E_{d}}{\beta} \leq T_{d}<\infty
\end{array}\right]
$$

Where $T_{d}$ is the damage energy; $E_{d}$ is the threshold energy and represents the energy required to create a stable Frenkel pair, and $\beta$ is equal to 0,8 factor which was determined from binary collision formula.

E521 ASTM standard practice for neutron radiation damage simulation by charged particle irradiation suggests the use of the NRT secondary displacement model which allows for calculating environmentally independent damage, and although it is not necessarily accurate it is an internationally recognized standard which allows comparison to dpa correlations from neutron damage [26]. Figure 2 shows ASTME693 Standard particle [25] as an example for characterizing neutron in iron and low alloy steels in terms of the dpa. In this figure, energy depends on dpa-neutron cross section which is multiplied with neutron incident energy spectrum to calculate dpa-cross section. 


\section{Methodology}

The Monte Carlo transport simulation code (MCNP) has been used to model the interaction of neutrons within iron. The cylindrical geometry was consisted of a bucket which is rounded by $2 \mathrm{~cm}$ of length, $1 \mathrm{~cm}$ of high and $1 \mathrm{~cm}$ of thickness for target iron. The target iron consists of $\left(5,9 \%{ }^{54} \mathrm{Fe}, 9,1 \%{ }^{56} \mathrm{Fe}, 2,1 \%{ }^{57} \mathrm{Fe}\right.$ and $\left.0,28 \%{ }^{58} \mathrm{Fe}\right)$ which are surrounded by air. For the slab geometry, the parameters described mono-directional source neutrons which emitted from a $1,5 \mathrm{~cm} \times 1,5 \mathrm{~cm}$ square surface source, placed $1,5 \mathrm{~cm}$ from the slab of natural iron. And then the neutron source was placed inside the bucket on the bottom. Once important parameter was F12: N4 which means, we are looking the number of neutron on the surface, which was cylindrical outside of the bucket.

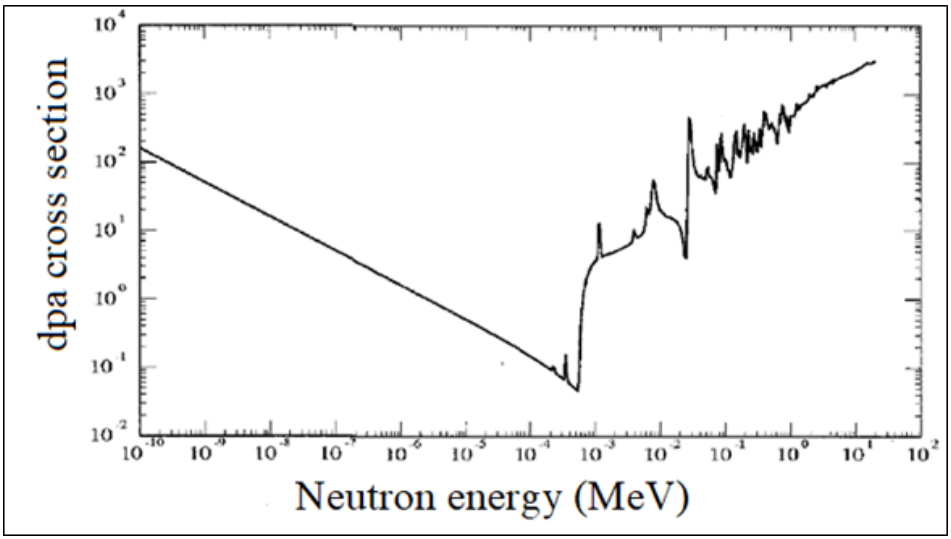

Fig. 2. Dpa cross section as a function of neutron energy for Fe [28]

Next, the first simulation was started by running (20000 and 40000 ) histories for $2 \mathrm{MeV}$ neutron source. And the graph was plotted between the number of histories and the statistical tests, which were found them from the output file.

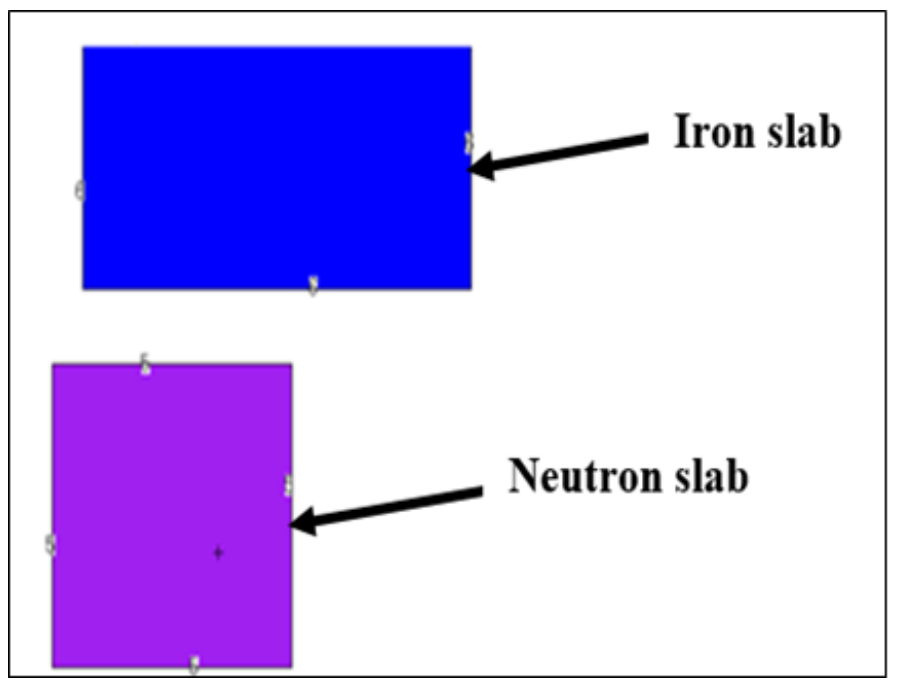

Fig. 3. Illustration of a slab geometry plotted by means of MCNPX. The blue colour denotes iron slab (top) and the purple colour denotes neutron source (bottom) 


\section{Result and discussion}

Once important thing is the reliability of the result of the test, which can be determined either by passing all the ten statistical testes particularly the relative error, or it can be determined by considering on the figure of merit (fom). Therefore, two graphs were plotted of the 20000 and 40000 numbers of histories against (fom) for each $2 \mathrm{MeV}$ and Watt spectrum neutron source. From these two points, it was found that the result obtained by running 20000 numbers of histories of the $2 \mathrm{MeV}$ neutron source is not reliable as one of the tallies in the tally fluctuation chart bin did not pass from the statistical test. Moreover, one of the tallies had bins with relative errors greater than recommended, and the percentage error in this situation, which was found from output file, is as higher as $33 \%$. The total number of neutron flux, which was passed through the cylindrical surface was about 2,96926E-04 of neutrons per each $\mathrm{cm}^{2}$, with having 0,0172 of error. Therefore, the number of histories where increased to 40000 histories, and then the MCNP code was again run. It can be seen in figure 4 that the figure of merit tends to be flat at the end of the way. Furthermore, although, all the statistical testes were not passed, the value of that tally, which did not pass for 20000 histories, was increased to 2,70 that not be less than 3 . And the total number of neutron flux was increased to $2,98448 \mathrm{E}-04$ neutrons per $\mathrm{cm}^{2}$ with having less error 0,0119.

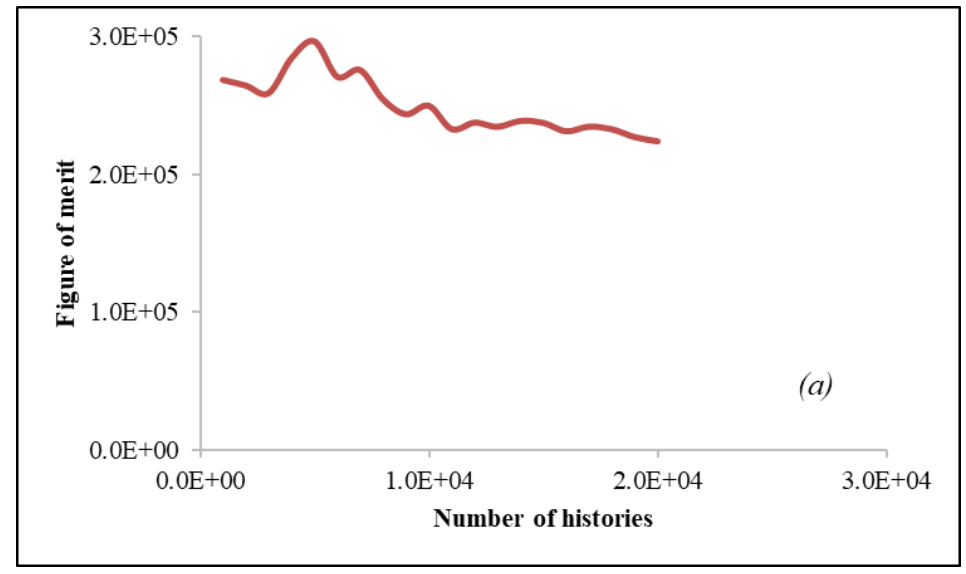

Fig. 4. The relationship of number of histories against figure of merit with (a) 20000 (b) 40000

There are two types of methods which calculate the dpa with model of specific geometry. The first one calculates flux and fold with dpa cross section. The second one calculates dpa directly with the MCNP (HISTP/ HTAPE). Both types of methods produces radiation damage energy cross section [5;7]. The dpa was calculated using the radiation damage cross sections which are not able to a part of the MCNP cross section libraries. MCNP cross section is developed by using (NRT) or new methods such as advanced models molecular dynamics simulation coupled with the binary collision approximation or other simulation methods [27]. The flux in MCNP as a function of energy was tallied by using the F4 tally (F4 is necessary to carry out the calculations) which multiplied by the neutron dpa cross section for iron material. Therefore, the dpa was calculated in MCNP which calculated by:

$$
\mathrm{dpa}=\int \sigma_{\mathrm{disp}}(E) \frac{d \varnothing(E)}{d E} d E .
$$


Hence, the parameters $\varnothing(E)$ and $\sigma_{\text {disp }}(E)$ are the flux-spectrum (particles $/ \mathrm{cm}^{2}$ ) and the displacement cross section (barns).

Figure 5 shows a plot of the absorption cross section for neutron by using iron slab in different layers of the shield. It can be clearly seen that as neutron energy increases, dpa cross section decreases until a minimum is reached, after that it stays constant as well as then fluctuating dramatically towards the end of the plot. However, this trend is evidenced in every layer of the shield but in comparison to the other layers iron shows a much shorter plateau that has a shoulder-like decrease which is immediately followed by sharp fluctuations. This makes the plot falls below that of lead. This evidence shows at energies between $10^{-3}$ and $10^{-2} \mathrm{MeV}$. MCNP was calculated using the number of the displacement per atom by using tally. So, the maximum number of atomic displacement was about 5,60E-01 dpa.

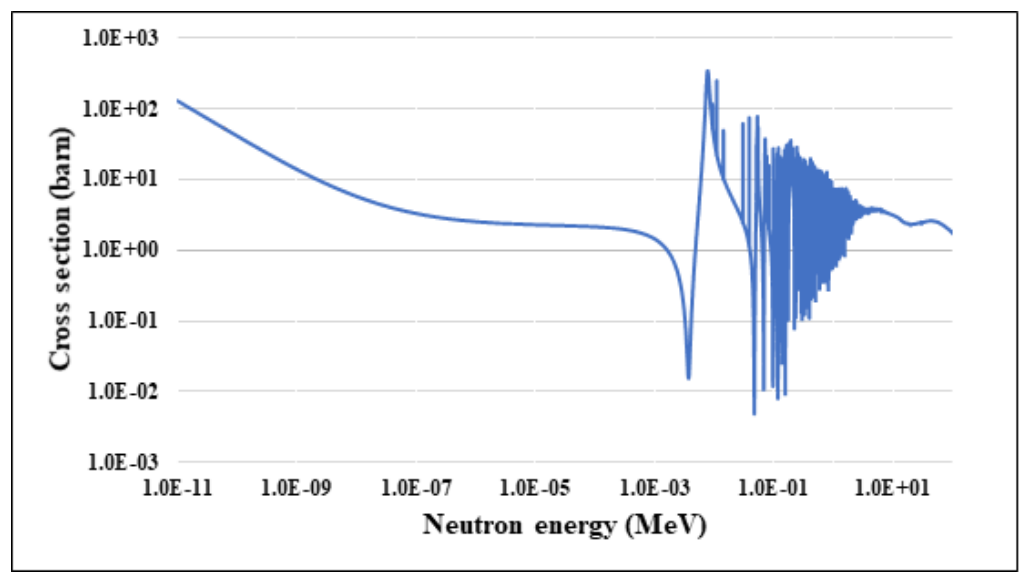

Fig. 5. Displacement cross section as a function of neutron energy for Fe

\section{Conclusion}

This paper shows how to use MCNP method to calculate the neutron cross section on a surface and also how to use MCNP geometry problem description. Calculations have been performed by Monte Carlo method to model the interaction of neutrons with iron. Then, MCNP was calculated using the F4 tally for determining the number of dpa cross section. The results observed that as neutron energy increases, dpa cross section decreases, after that it stays constant and then fluctuating dramatically towards the end plot.

\section{REFERENCES}

1. Amirkhani M.A., Asadabad M.A., Hassanzadeh M., Mirvakili S.M., Mohammadi A. Calculation of Dpa Rate in Graphite Box of Tehran Research Reactor (TRR). Nuclear Science and Techniques, 2019, vol. 30, no. 6, article ID: 92. DOI: 10.1007/s41365-019-0621-3.

2. Azevedo C. A Review on Neutron-Irradiation-Induced Hardening of Metallic Components. Engineering Failure Analysis, 2011, vol. 18, no. 8, pp. 1921-1942. DOI: 10.1016/j.engfailanal.2011.06.008.

3. Baumgärtner A., Burkitt A., Ceperley D., De Raedt H., Ferrenberg A., Heermann D., Herrmann H., Landau D., Levesque D., von der Linden W. The Monte Carlo Method in Condensed Matter Physics. Berlin, Springer Science \& Business Media, 2012. $360 \mathrm{p}$.

ISSN 2587-6325. Математ. физика и компьютер. моделирование. 2021. Т. 24. № 1 
4. Brown F.B., Barrett R., Booth T., Bull J., Cox L., Forster R., Goorley T., Mosteller R., Post S., Prael R. MCNP Version 5. Trans Am Nucl Soc, 2002, vol. 87, no. 273, pp. 023935.

5. Feghhi S.A.H., Gholamzadeh Z. A MCNP Simulation Study of Neutronic Calculations of Spallation Targets. Nuclear Technology \& Rsdiation Protection, 2013, vol. 28, no. 2, pp. 128136.

6. Forster R.A., Cox L.J., Barrett R.F., Booth T.E., Briesmeister J.F., Brown F.B., Bull J.S., Geisler G.C., Goorley J.T., Mosteller R.D. MCNP ${ }^{\mathrm{TM}}$ Version 5. Nuclear Instruments and Methods in Physics Research Section B: Beam Interactions with Materials and Atoms, 2004, vol. 213, pp. 82-86. DOI: 10.1016/S0168-583X(03)01538-6.

7. Hashem J.A. Automating X-Ray and Neutron Imaging Applications with Flexible Automation. UT Electronic Theses and Dissertations. URL: http://hdl.handle.net/2152/33357.

8. Hiwa M., Ari M. Investigation of Long and Short Term Irradiation Hardening of P91 and P92 Ferritic/Martensitic Steels. Voprosy atomnoj nauki i tekhniki. Seriya: Termoyadernyj sintez [Problems of Atomic Science and Technology, Ser. Thermonuclear Fusion], 2019, vol. 42, no. 2, pp. 81-88. DOI: 10.21517/0202-3822-2019-42-2-81-88.

9. Hiwa M. Stopping Power of Alpha Particles in Helium Gas. Vestnik Moskovskogo gosudarstvennogo tekhnicheskogo universiteta im. N.E. Baumana Seriya "Estestvennye nauki" [Herald of the Bauman Moscow State Technical University. Series Natural Sciences], 2020, vol. 89, no. 2, pp. 117-125. DOI: 10.18698/1812-3368-2020-2-117-125.

10. Khadem M.M.R.K., Piya S., Shamsuzzoha A. Quantitative Risk Management in Gas Injection Project: a Case Study from Oman Oil and Gas Industry. Journal of Industrial Engineering International, 2018, vol. 14, no. 3, pp. 637-654. DOI: 10.1007/s40092-017-0237-3.

11. Mahmoud K., Rammah Y. Investigation of Gamma-Ray shielding capability of glasses doped with Y, Gd, Nd, Pr and Dy rare earth using MCNP-5 code. Physica B: Condensed Matter, 2020, vol. 577, article ID: 411756. DOI: 10.1016/j.physb.2019.411756.

12. $M C N P^{T M}-A$ General Monte Carlo N-Particle Transport Code. Version 4C. URL: https://permalink.lanl.gov/object/tr?what=info:lanl-repo/lareport/LA-13709-M.

13. Norgett M., Robinson M., Torrens I. Standard Practice for Neutron Radiation Damage Simulation by Charged-Particle Irradiation (Designation E 521-96). Annual book of ASTM standards. West Conshohocken, American Society for Testing Materials International, 2009, vol. 12.02, pp. 141-160.

14. Phythian W., Stoller R., Foreman A., Calder A., Bacon D. A Comparison of Displacement Cascades in Copper and Iron by Molecular Dynamics and its Application to Microstructural Evolution. Journal of Nuclear Materials, 1995, vol. 223, no. 3, pp. 245-261. DOI: 10.1016/0022-3115(95)00022-4.

15. Qadr H.M. Calculation for Gamma Ray Buildup Factor for Aluminium, Graphite and Lead. International Journal of Nuclear Energy Science and Technology, 2019, vol. 13, no. 1, pp. 61-69. DOI: 10.1504/IJNEST.2019.099718.

16. Qadr H.M. Comparison of Energy Resolution and Efficiency of NaI (TI) and HPGe Detector Using Gamma-Ray Spectroscopy. Journal of Physical Chemistry and Functional Materials, 2020, vol. 3, no. 1, pp. 24-27.

17. Qadr H.M. Calculation of Gamma-Ray Attenuation Parameters for Aluminium, Iron, Zirconium and Tungsten. Voprosy atomnoj nauki $i$ tekhniki. Seriya: Termoyadernyj sintez [Problems of Atomic Science and Technology, Ser. Thermonuclear Fusion], 2020, vol. 43, no. 2, pp. 25-30. DOI: 10.21517/0202-3822-2020-43-2-25-30.

18. Qadr H. Effect of Ion Irradiation on the Hardness Properties of Zirconium Alloy. Annals of the University of Craiova, Physics, 2019, vol. 29, pp. 68-76.

19. Qadr H. Effect of Ion Irradiation on the Mechanical Properties of High and Low Copper. Atom Indonesia, 2020, vol. 46, no. 1, pp. 47-51. DOI: 10.17146/aij.2020.923.

20. Qadr H.M., Hamad A.M. Mechanical Properties of Ferritic Martenstic Steels: A Review. Scientific Bulletin of Valahia University-Materials and Mechanics, 2019, vol. 17, no. 16 , pp. 18-27. DOI: 10.2478/bsmm-2019-0003. 
21. Raychaudhuri S. Introduction to Monte Carlo Simulation. Proceedings of the 2008 Winter Simulation Conference. URL: https://www.informssim.org/wsc08papers/012.pdf.

22. Sahin H.M. Monte Carlo Calculation of Radiation Damage in First Wall of an Experimental Hybrid Reactor. Annals of Nuclear Energy, 2007, vol. 34, no. 11, pp. 861-870. DOI: $10.1016 / \mathrm{j}$.anucene.2007.04.011.

23. Salazar-Cravioto H., Nieto-Perez M., Ramos G., Mahajan S., Valanju P., Kotschenreuther M. Modeling of a Spherical Tokamak as an Extended Neutron Source Using ASTRA and MCNP. IEEE Transactions on Plasma Science, 2020, vol. 48, iss. 6, pp. 1810-1816. DOI: 10.1109/TPS.2020.2990559.

24. Shultis J., Faw R. An MCNP Primer. URL: https://www.mne.kstate.edu/ jks/MCNPprmr.pdf.

25. Standard Practice for Characterizing Neutron Exposure in Iron and Low Alloy Steels in Terms of Displacements Per Atom (dpa). URL: https://www.astm.org/DATABASE.CART/HISTORICAL/E693-94.htm. DOI: 10.1520/E069394.

26. Standard Practice for Neutron Radiation Damage Simulation by ChargedParticle Irradiation. URL: http://www.astm.org/cgi-bin/resolver.cgi?E521-96(2009)e1. DOI: 10.1520/E0521-96R09E01.

27. Stoller R. 1.11-Primary Radiation Damage Formation. Comprehensive Nuclear Materials, 2012, pp. 293-332.

28. Stoller R., Nordlund K., Simakov S. Summary Report of the Technical Meeting on Primary Radiation Damage: From Nuclear Reaction to Point Defects. International Atomic Energy Agency. URL: https://www.osti.gov/etdeweb/biblio/22069478.

29. Was G.S. Fundamentals of Radiation Materials Science: Metals and Alloys. Berlin, Springer, 2017. 985 p.

\section{ИСПОЛЬЗОВАНИЕ КОДА МСNР ДЛЯ РАСЧЕТА ПОВРЕЖДЕНИЙ, ВЫЗЫВАЕМЫХ РАДИАЦИЕЙ}

\section{Моххамед Кадр Хива}

Ассистент кафедры физики научного колледжа,

Университет Рапарина

hiwa.physics@uor.edu.krd

https://orcid.org/0000-0001-5585-3260

Мэйн-стрит, г. Ранья, Ирак

Аннотация. В работе детально анализируются результаты численных экспериментов, выполненных в рамках метода Монте - Карло с использованием программного кода MCNP. Описаны базовые принципы стохастической теории переноса излучения, подробно обсуждается метод случайных траекторий для решения задач Монте - Карло. В данной работе код MCNP использован для численной оценки величины нейтронного потока. Исследовано влияние первичного радиационного повреждения, вызываемого в железе при его облучении высокоэнергетическими нейтронами. В качестве измеряемой характеристики радиационного повреждения использована величина смещения на атом (displacement per atom, dpa) в веществе как функция энергии нейтрона. Проведены численные исследования поперечного сечения dpa.

Ключевые слова: нейтронное повреждение, MCNP, смещение на атом, метод NRT, вычислительные алгоритмы.

ISSN 2587-6325. Математ. физика и компьютер. моделирование. 2021. T. 24. № 1 